ISSN 0103-5150

Fisioter. Mov., Curitiba, v. 26, n. 2, p. página 291-305, abr./jun. 2013

Licenciado sob uma Licença Creative Commons

\title{
Ensino e práticas da fisioterapia aplicada à criança na formação do fisioterapeuta
}

\author{
Teaching and practice of physical therapy applied \\ to vocational training of the child
}

\author{
Maria José de Paula Guedes ${ }^{[a]}$, Nildo Batista Alves ${ }^{[b]}$, \\ Rozangela Maria de Almeida Fernandes Wyszomirska ${ }^{[c]}$
}

[a] Especialista em Saúde Mental Infantojuvenil pela Universidade Estadual de Ciências da Saúde de Alagoas (Uncisal), professora auxiliar do curso de Fisioterapia da Universidade Estadual de Ciências da Saúde de Alagoas (Uncisal), Maceió, AL - Brasil, e-mail: mjdpg@uol.com.br

[b] Doutor em Medicina (Pediatria) pela Universidade de São Paulo (USP), professor titular da Universidade Federal de São Paulo (Unifesp), São Paulo, SP - Brasil, e-mail: nildobatista@unifesp.br

[c] Doutora em Clínica Médica pela Universidade Estadual de Campinas (Unicamp), professora adjunta da Universidade Estadual de Ciências da Saúde de Alagoas (Uncisal), Maceió, AL - Brasil, e-mail: rozangelaw@yahoo.com.br

\section{Resumo}

Introdução: É um dos desafios delegados aos docentes da Fisioterapia formar profissionais conhecedores do que é particular na abordagem à criança, no intuito de favorecer estratégias ambientais e sociais favoráveis ao desenvolvimento potencial da criança. Objetivo: Investigar o ensino e a aprendizagem da Fisioterapia aplicada à criança, nos cursos de Fisioterapia de Alagoas. Métodos e materiais: Estudo exploratório, descritivo, construído a partir de uma abordagem qualitativa e quantitativa, realizado com docentes responsáveis pelo ensino e egressos dos cursos de Fisioterapia do estado. 0 procedimento adotado é a análise documental do plano de ensino do curso; aplicação de questionário utilizando escala de Lirket aos alunos e entrevistas com os professores, obedecendo a núcleos direcionadores para análise temática. Resultados: Foi percebido que o ensino de Fisioterapia aplicada à criança em Alagoas sofre as consequências do crescimento explosivo do número de cursos, ocorrido nesta última década; demonstra práticas tradicionais da Fisioterapia, voltada para as doenças, entre estas as neurológicas e afecções respiratórias. Os professores com formação docente indicaram iniciativas em metodologias ativas e visão mais intregral da saúde das crianças. Conclusão: Docentes 
e egressos sugerem alterações no projeto pedagógico, com ampliação e antecipação das vivências práticas, inserção de novos conteúdos disciplinares e ampliação da carga horária; mudanças na metodologia de ensino com ampliação da problematização no ensino e mais apoio institucional a essas mudanças; implementação de ações inter e multidisciplinares; melhorias na articulação teórico-prática.

Palavras-chave: Ensino. Fisioterapia. Saúde da criança.

\section{Abstract}

Introduction: One of the challenges delegates to train teachers of physical therapy professionals who is particularly knowledgeable in the approach to the child, in order to promote environmental strategies and social development potential of children. Objective: To interrogate the teaching and learning of physical therapy applied to the child, in physiotherapy courses of Alagoas State, Brazil. Methods and materials: Exploratory, descriptive, constructed from a qualitative and quantitative approach, conducted with teachers responsible for teaching and graduates of the State Physical Therapy. The procedure adopted is a documentary analysis of the syllabus of the course, using a questionnaire scale Lirket students and interviews with teachers, following the core direction positioners for content analysis. Results: It was perceived that the teaching of Physical Therapy in Alagoas State applied to the child suffers the consequences of explosive growth in the number of courses, which occurred in the last decade, demonstrates the traditional physical therapy practices, focused on the disease, among these the neurological and respiratory problems. Teachers with teacher training have demonstrated, active methodologies and initiatives integral vision of children's health. Conclusion: Faculty and graduates suggest changes in the educational project, with anticipation of expansion and practical experiences, adding new content and expanding the disciplinary workload, changes in teaching method with amplification of questioning in teaching and more institutional support for these changes, implementation of actions inter-and multidisciplinary, improvements in theoretical-practical articulation.

Keywords: Teaching. Physical therapy Child health.

\section{Introdução}

A abordagem à criança não se encerra nela; deve ser direcionada à criança e às suas circunstâncias. A formação profissional deve habilitar o fisioterapeuta para ser o consultor da família, muitas vezes o interventor nas fases mais precoces de riscos, como no período pré-natal, e ainda procurar ser o mediador em tudo que promova bem-estar à criança. 0 profissional da saúde, para cumprir essa tarefa, terá que exercer o papel de educador, de ecologista, desenvolvendo uma visão holística da saúde (1).

É um dos desafios delegados ao docente em saúde formar profissionais conhecedores do que é particular na abordagem à criança; eles devem ser habilidosos no ato de desenvolver estratégias ambientais e sociais favoráveis ao desenvolvimento potencial da criança, pois o ambiente social favorável impulsiona a aquisição de habilidades, favorece a independência funcional e também melhora o desempenho escolar $(2,3)$.
As pesquisas relacionadas ao ensino em Fisioterapia são escassas. Talvez, uma das justificativas para não se realizar pesquisas seja a dificuldade de encontrar um referencial teórico específico. Outra justificativa, que não anula a primeira, pode estar relacionada ao perfil docente com práxis focada na assistência, tendendo a realizar pesquisas dentro de sua especialidade, ficando as práticas pedagógicas relegadas ao segundo plano.

O professor fisioterapeuta que tem formação Stricto Sensu voltada para a educação apresenta uma visão mais clara a respeito das necessidades educacionais atuais. No entanto, as práticas pedagógicas mostram traços de ensino tradicional: privilégio de aulas expositivas focadas no professor; repasse de informações; avaliação somativa e apresenta dificuldades em adotar estratégias inovadoras na condução do processo de aprendizagem (4). As causas possíveis encontradas para justificar tal situação estão, muitas vezes, na contratação, pelas instituições de ensino superior (IES) particulares, de professores 
para atender especificamente uma ou outra disciplina, com pouco envolvimento no projeto pedagógico do curso e nas atividades curriculares de pesquisa e extensão. Outras situações apontadas seria o pouco compromisso em desenvolver ou qualificar os docentes pedagogicamente, com criatividade e reflexão sobre o modelo de ensino existente e, por fim, a pouca importância que se dá para avaliação institucional, às questões do aprimoramento no ensino de graduação causadas por inovações estratégicas de ensino. 0 que se avalia frequentemente é quantos professores se titularam e se tornaram mestres e doutores em um determinado período (5).

Com base na necessidade de formação diferenciada para o público infantil, esta pesquisa foi desenvolvida na tentativa de conhecer o ensino Fisioterapia aplicada à criança no estado de Alagoas.

Para suprir a necessidade de referencial teórico inerente a esta pesquisa, foram colhidas informações em outras áreas de conhecimento como na medicina, na enfermagem e na odontologia. São profissões que já pesquisaram um pouco mais o seu ensino.

0 ensino de Fisioterapia aplicada à criança, referido neste trabalho, compreende todo o conteúdo relacionado à criança dentro da graduação e não somente a disciplina constante na grade curricular dos cursos. Abrange também a Clínica Pediátrica, os estágios supervisionados e os conteúdos complementares dos cursos.

\section{Materiais e métodos}

As variáveis estruturais dos cursos e das disciplinas, a carga horária de ambos, o momento de inserção no curso, o número de docentes e o tempo de docência dos professores foram analisadas a partir de uma abordagem quantitativa. Outras variáveis como concepção da disciplina, atributos docentes, problemas do cotidiano do ensino, conteúdo e metodologia de avaliação foram analisadas por meio de uma abordagem qualitativa.

A pesquisa realizou-se em três instituições de ensino do estado de Alagoas. 0 estado conta com oito instituições de Ensino Superior que possuem curso de graduação em Fisioterapia. Dessas, quatro foram excluídas porque não apresentavam egressos até o período inicial da pesquisa, e uma não aceitou participar.

A população-alvo foi constituída por 11 docentes responsáveis pelas disciplinas relacionadas à fisioterapia aplicada à criança; e 105 fisioterapeutas egressos dos respectivos cursos no segundo semestre de 2009.

Optamos pelo uso da entrevista semiestruturada com os docentes, a qual permite alguma padronização que favorece a comparação de dados obtidos pelo conjunto de respostas, mas também é flexível, permitindo adaptações e obtenção de informações complementares (6). Seguiram-se os seguintes eixos direcionadores: o professor, sua trajetória docente, a concepção do ensino de Fisioterapia aplicada à criança, as estratégias avaliativas utilizadas. Todas as entrevistas foram gravadas com prévia autorização do entrevistado, transcritas na íntegra, catalogadas em ordem de realização, lidas e ouvidas inúmeras vezes, compiladas de acordo com seus eixos, submetidas a análise temática (7). Com os egressos foi utilizado questionário - definido como um número de perguntas apresentadas por escrito, objetivando o conhecimento de opiniões, crenças, sentimentos, interesses, expectativas, situações vivenciadas, entre outras (8). Para quantificar as respostas foi empregada a escala de Likert, a qual requer que os entrevistados indiquem seu grau de concordância com declarações relativas a atitudes que estão sendo medidas (9).

Antes da coleta de dados, os instrumentos foram submetidos a um pré-teste, com graduandos e docentes, com o objetivo de estimar o tempo gasto para responder ao questionário e detectar eventuais dificuldades na hora do preenchimento ou entendimento das questões propostas.

0 projeto de pesquisa foi previamente aprovado pelo Comitê de Ética em Pesquisa da Universidade Federal de São Paulo, protocolo 60310/10.

\section{Resultados e discussão}

A docência na graduação da Fisioterapia aplicada à criança

Participam do ensino de Fisioterapia aplicada à criança, nos cursos de Fisioterapia analisados no estado de Alagoas, 14 professores, dos quais, 11 foram entrevistados. Todos são do sexo feminino, com uma média de idade de 33 anos (com desvio padrão de 3.45), graduados em Fisioterapia há aproximadamente dez anos (variando de 2 a 17 anos) e portadores de Pós-Graduação Lato Sensu, nível especialização, em diferentes áreas de conhecimento. Apenas dois 
se especializaram em áreas correlatas à Fisioterapia aplicada à criança (Neurofisiologia e Psicofisiologia da Estimulação Precoce). É importante ressaltar que dois são especialistas em Terapia Intensiva, três em Fisioterapia Cardiorrespiratória e os demais em outras áreas da Fisioterapia. Dois professores possuem especialização em Docência do Ensino Superior. Apenas um professor possui titulação de mestre.

0 tempo médio de docência na área foi de 5,63 anos, variando de 1 a 12 anos. Nove professores exercem atividades profissionais em Fisioterapia aplicada à criança. Além das atividades docentes, quatro prestam assistência exclusivamente hospitalar, dois exclusivamente ambulatoriais, dois, assistência ambulatorial e hospitalar e, por fim, uma professora presta assistência em domicílio. Seis professores são de Alagoas e cinco de outros estados: Ceará, Sergipe, São Paulo, Paraná e Rio Grande do Sul.

A baixa titulação acadêmica do corpo docente deve-se ao aumento do número de novos cursos de Fisioterapia no Brasil nas duas últimas décadas. A expansão desregulada, desencadeando problemas da mercantilização da Educação Superior, destacando-se inexistência de planejamento, baixa qualidade de ensino e desequilíbrio entre áreas de conhecimento e entre regiões geográficas (9).

No Estado de Alagoas, até 1997, não existia nenhum curso de Fisioterapia credenciado pelo MEC, para, em 2010, contar com oito novos cursos, todos concentrados na capital do estado.

Em nível nacional, o curso de graduação em Fisioterapia foi o que mais cresceu ao longo do período 1991-2004, mostrando um crescimento de $741,5 \%$ nas matriculas de alunos, contra uma média nacional de 150,7 para os demais cursos da área de saúde (10), Entre 1995 e 1998, passou de 63 para 115 cursos, o que corresponde a um crescimento de mais de $80 \%$. Entre 1999 a 2003, o número saltou de 115 para 298, o que representa aumento de $159 \%$ em apenas cinco anos; nos cinco anos posteriores, o crescimento de $60 \%$ levou ao total de 479 cursos em 2008. Resumindo, nos últimos dez anos, a quantidade de curso e a oferta de vagas de Fisioterapia no Brasil aumentaram em mais de $300 \%$, com a criação de 364 novos cursos. 0 fator determinante para essa expansão foi corrigir o deficit da escolaridade superior no país (11).

No entanto, o ensino da Pós-Graduação Strictu Sensu, mestrado e doutorado, não acompanhou este crescimento, faltando docentes capacitados. A lei de
Diretrizes e Bases da Educação Nacional de 1996 (12), em seu Artigo 52, inciso II, estabelece o prazo de oito anos para que as Universidades apresentem "um terço do corpo docente, pelo menos, com titulação acadêmica de mestrado ou doutorado". A criação de novos cursos de Pós-Graduação na área de Fisioterapia seria um mecanismo concreto de atender ao grande número de cursos de graduação em funcionamento (13).

É necessário preparar a Universidade para o desempenho de um papel que corresponda às suas reais características, ou seja, realizar pesquisas educacionais e didáticas; estudar modelos alternativos de formação e preocupar-se com a formação dos formadores (14). A formação dos formadores torna-se difícil por não haver tradição de cursos destinados à preparação pedagógica do professor de 3ํo grau e também por sentimentos de perda do status ou de não reconhecimento do valor da formação pedagógica. Muitos professores resistem a participar de programas de formação ou aperfeiçoamento nessa área (15).

No núcleo direcionador "trajetória docente", foram identificadas, nas falas dos entrevistados, 28 Unidades de Registro (UR). Estas foram agrupadas em quatro categorias com suas respectivas subcategorias:

\section{a) Ingresso circunstancial}

0 ingresso circunstancial na carreira docente predomina na trajetória dos professores de Fisioterapia aplicada à criança: "Fui substituir uma professora que estava de licença" (Sujeito A). Foi observada, na fala de um professor, uma trajetória para a fisioterapia aplicada à criança, marcada pela necessidade da própria instituição: "Por questões administrativas institucionais, precisei ficar em respiratória e pediatria" (Sujeito C).

0 ingresso na área de Fisioterapia aplicada à criança em decorrência de experiência na assistência fisioterapêutica aparece como a segunda categoria mais frequente de ingresso na docência: "Através da experiência que eu já tinha na assistência" (Sujeito E); "Eu esperei amadurecer, ter bastante experiência [...] foi um planejamento" (Sujeito L). Um dos docentes ressalta sua experiência específica com a fisioterapia aplicada à criança: "Trabalhei em dois hospitais unicamente pediátricos" (Sujeito E).

A afinidade com a área específica da pediatria é também apontada como categoria de trajetória 
docente para a fisioterapia aplicada à criança: "Fui monitora de pediatria, fiz estágios extracurriculares [...] eu realmente me identificava com pediatria" (Sujeito D); "Sempre tive habilidades na época de estudante com Pediatria" (Sujeito F); "Na graduação eu já me identifiquei com a área” (Sujeito C).

A identificação com a docência aparece, para alguns professores, como motivadora do início da carreira na área da Fisioterapia aplicada à criança: "Achava que durante a apresentação de trabalhos me saía bem do ponto de vista de explicação aos meus colegas" (Sujeito D); "[...] desde a época de acadêmica eu já me identifica com o ensino" (Sujeito F). Foi também ressaltado, na fala de um professor, que a admissão favoreceu a formação docente: "Assim que a gente passou[...] a própria (INST) nos ofereceu uma espécie de um curso de docência" (Sujeito E).

Configura-se, dessa forma, uma pluralidade de motivações para ingressar na docência em Fisioterapia, dado que corrobora achados de estudos realizados no âmbito da docência universitária em Saúde (16, $17,18)$. Essa pluralidade reflete a complexa rede de interações sociais nas quais os professores do Ensino Superior se tornam docentes. A maneira como alguém se torna professor é histórica e está vinculada às suas relações sociais (19).

A identidade do professor não é um dado adquirido, mas um lugar de lutas e conflitos, um espaço de construção de maneira de ser e estar na profissão. A maneira como cada um ensina está dependente daquilo que ele é como indivíduo quando exerce o ensino (20).

0 progresso da escola tem relação direta com a profissionalização do professor, mas este é resistente à mobilização coletiva, às práticas reflexivas e à participação crítica (21). As iniciativas de grupos docentes devem ser incentivadas, criando condições solidárias e de apoio, para que seja possível a discussão e a organização da docência (22).

As concepções dos professores sobre a criança foram outro núcleo direcionador das entrevistas. Todos reconhecem especificidades na criança: "A criança não é um adulto pequeno, são totalmente diferentes" (Sujeito I). Na análise temática desse núcleo, identificamos 126 unidades de registro, das quais emergiram quatro categorias com suas respectivas subcategorias. Os professores reconhecem uma natureza biológica diferenciada na criança. "A fisiologia da criança é diferente, a anatomia da criança é diferente" (Sujeito D).
A caracterização da criança relacionada diretamente a uma concepção de faixa etária é marcante nas falas de alguns professores: "Entrar como pediatria é de zero a doze anos" (Sujeito L). Outros professores consideram a criança um ser em processo de desenvolvimento: "Pessoas que ainda estão em caráter de crescimento e desenvolvimento progressivo" (Sujeito J). A compreensão e experiência do que é ser criança modifica-se cronologicamente, de sociedade em sociedade e dentro da mesma sociedade. A palavra "criança" deriva do latim creantia, criantia; o termo, assim como o discurso acerca de sua significação, tem sofrido influências do momento histórico, da cultura ou da relação que estabelecem com aqueles que os rodeiam (23).

Na Declaração Universal dos Direitos da Criança, proclamada pela $\mathrm{ONU}$, consta que criança é qualquer pessoa com menos de 18 anos de idade. Para o Estatuto da Criança e do Adolescente (ECA), no Brasil, a separação entre criança e adolescente se funda tão somente no aspecto ligado à idade, não se levando em consideração o psicológico e o social. Ao se referir ao "estado" de criança e adolescente, caracterizam-se aqueles seres humanos em peculiares condições de desenvolvimento. Dessa forma, define-se a criança como a pessoa que tem 12 anos incompletos e o adolescente, o que se encontra na faixa etária dos 12 aos 18 anos de idade (24).

Para a sociedade Brasileira de Pediatria, a atuação do pediatra estende-se desde a concepção até o término do crescimento somático do indivíduo abrangendo a atuação do pediatra até os 18 anos de idade (25).

Do ponto de vista físico, o desenvolvimento da criança não significa apenas aumento de tamanho, mas também que certos elementos se modificam e se adaptam durante o processo de maturação de acordo com a genética, com as experiências e com as exigências do ambiente (26).

b) Especificidade emocional da criança

A segunda categoria emergente foi a especificidade emocional da criança. Os professores enfatizam a importância do reconhecimento dessas especificidades para viabilizar a terapêutica: "Pelo fato de um ser bem mais sensível" (Sujeito B).

Ao comparar a criança de hoje com as nascidas durante o século XIX, observa-se que, apesar de tantas mudanças ocorridas, ainda não são vistas como seres 
autônomos na sua capacidade de pensar, querer e sentir. Há tendência a vê-las como seres dependentes e que necessitam ser protegidas. Para Dallari e Korczac (27):

\begin{abstract}
A preocupação com a proteção da criança não deve servir de pretexto para anulação de sua criatividade, assim como a indiferença pela criança não pode ser confundida com o respeito por sua liberdade. É preciso que se conjuguem ambos, a proteção e o respeito, para que a criança possa exercer em toda plenitude, o seu direto de viver. E viver é participar da vida, é acrescentar alguma coisa à criação, é imprimir sua marca no mundo criado. Desse modo, o exercício do direito a vida deve ser constante prática do pensar, do falar e do agir, da expressão livre, do diálogo [...].
\end{abstract}

0 respeito à criança por parte dos profissionais da Saúde inclui, dentre outras práticas, a permissão para que ela participe ativamente do planejamento do processo assistencial, recebendo informações, sendo consultada, fazendo as escolhas possíveis; ou seja, sendo tratada como sujeito de direitos (28).

Os professores ressaltam a importância de considerar a formação de vínculo e a dependência afetiva da criança para haver interação no momento terapêutico: "Ela precisa saber que aquele tratamento vai ser bom" (Sujeito F). Os professores fazem também referência às especificidades da comunicação com a criança. "Não consegue expressar aquilo que incomoda" (Sujeito H).

A interação entre médico e paciente criança deve ser afetiva e amistosa, mas não podem ser esquecidos dois aspectos fundamentais na relação médico-paciente: a troca de informações e a tomada de decisões. Os pais oferecem informações importantes, mas não se pode assumir, a priori, que a percepção que eles têm da doença reflita com precisão os sentimentos e necessidades dos filhos, especialmente quando estes vão se tornando mais independentes (29).

Em estudo realizado na Inglaterra, foi observado que a opinião, os sentimentos e informações das crianças raramente são levados em conta nos serviços de saúde. Os autores acreditam que não se trata de falta de interesse pelo que a criança pensa, mas da dificuldade dos médicos em abordá-las verbalmente ou uma tentativa de protegê-las de informações, que poderiam perturbá-las emocionalmente (30).

Características e necessidades no aprendizado motor são também apontadas por alguns professores:
"Precisa de concentração pra aprender" (Sujeito H). Para aprender, o organismo humano conta com dois princípios básicos e universais da Biologia: estrutura e adaptação (31). Assim como existem estruturas específicas para cada função do organismo, também existe estrutura para o ato de conhecer. Essa estrutura não aparece pronta no organismo; possui sua gênese nos reflexos que se transformam em esquemas motores. Pela ação, a criança constrói gradativamente suas estruturas cognitivas que se manifestam numa organização sequencial chamada de desenvolvimento cognitivo (31).

Dessa forma, a ação da criança sobre o meio produz conhecimento funcional cada vez mais complexo, por criar constantemente novas combinações ou novos esquemas (32). Nessa perspectiva, o que se pode perceber é uma estruturação cognitiva progressiva.

Piaget especifica quatro fatores responsáveis pela psicogênese do intelecto infantil: o fator biológico, particularmente o crescimento orgânico e a maturação do sistema nervoso; o exercício e a experiência física; as interações e transmissões sociais, que se dão basicamente por meio da linguagem e da educação; e o fator de equilibração das ações, o qual está relacionado ao conceito de homeostase da biologia (31).

\section{c) Abordagem terapêutica diferenciada na criança}

A terceira categoria emergente das falas dos professores foi a necessidade de uma abordagem terapêutica diferenciada na criança: " $A$ forma de tratar, a forma de abordar é diferente" (Sujeito I). Os professores apontam particularidades da relação técnica com a habilidade manual na abordagem terapêutica direcionada à criança: "Vai precisar mais de um par de mãos e um par de pernas" (Sujeito F). Alguns professores atentam ainda para o caráter preventivo da abordagem terapêutica na criança: "Necessitam da intervenção precoce". "Atenção especial porque é o futuro do nosso planeta" (Sujeito E).

A fisioterapia, ao longo de sua história, atuou de modo prioritário no nível terciário, destinando-se à cura de determinadas enfermidades e/ou à reabilitação de sequelas e complicações. A atuação dirigida apenas para a reabilitação impõe restrições à prática do fisioterapeuta, que se limita a intervir quando a doença já está instalada e, na maioria dos casos, de forma avançada. Esses fatores têm contribuído para a dificuldade de ampliação do campo de atuação da 
Fisioterapia, em virtude do inadequado perfil profissional para atuação em outros níveis (33).

A estrutura, a metodologia de ensino e a organização curricular dos cursos de Fisioterapia ainda não se baseiam nas demandas sociais e nas políticas públicas de Saúde, e existe pouco envolvimento dos egressos e docentes com políticas institucionais e governamentais (34).

0 caráter individualizado da Fisioterapia aplicada à criança é também ressaltado: "Trabalhar de acordo com a faixa etária" (Sujeito I). Segundo a teoria do desenvolvimento cognitivo de Piaget, o desenvolvimento da inteligência da criança se processa por estágios delimitados por faixa etária que não necessariamente coincidem com a sua idade cronológica, podendo acontecer variações, apesar de não ocorrerem variações na sequência (35).

\section{d) Envolvimento familiar na terapêutica}

A quarta categoria emergente entre os professores é o reconhecimento do envolvimento familiar na terapêutica aplicada à criança: "Se não tiver uma interação grande com esse grupo, o seu tratamento não vai ser eficaz" (Sujeito B). O desenvolvimento infantil em concordância com a política de bem-estar nos cuidados primários de saúde e educação é considerado prioridade para a Organização Mundial de Saúde, União Europeia e por todos aqueles que apostam no progresso das comunidades.

A construção dos afetos e da autoestima se estabelece precocemente nas relações interpessoais no seio da família. A família é o primeiro modelo de escola para a criança. E deve ser o primeiro alvo de intervenção em Saúde e Educação, entendendo que saúde e escola definem-se no contexto da família. Portanto, quaisquer ações que envolvam a continuidade do desenvolvimento infantil terão que ser complementares da dinâmica do modelo familiar, partindo do princípio de que na família há projetos e práxis de bem-estar (1).

Em estudo desenvolvido com mais de 80 crianças hospitalizadas, observou-se que, quando a criança e/ ou pais não são consultados, eles podem protestar contra a decisão tomada pelos profissionais (36). Essas autoras consideraram que quando a criança e a família participam da tomada de decisões, a criança desenvolve autoestima e os pais se sentem parte da equipe. Concluem que, dessa forma, há melhores condições para a realização de um cuidado mais harmonioso e consistente durante a hospitalização.

O uso de estratégias para cuidar do familiar/ acompanhante tem como base a comunicação efetiva e o relacionamento interpessoal. A prática de escuta e acolhimento já mostrou bons resultados $(37,38)$.

Cuidar dos pais, por meio de grupos de apoio, pode ser um caminho para avançar nos cuidados prestados à criança (39) e, para isso, o profissional da Saúde precisa desenvolver conhecimento específico para melhor compreender o funcionamento e a dinâmica grupal (40).

Para tornar a permanência da família na unidade mais agradável, além do preparo dos profissionais de Saúde nas relações interpessoais, será necessário, flexibilizar o projeto terapêutico, de modo que a família encontre sua maneira de participar dos cuidados de forma prazerosa. Para isso, a equipe possivelmente precisará reorganizar seu processo de trabalho, levando em conta as aptidões da família e suas necessidades de cuidado (41).

Ensino e aprendizagem da Fisioterapia aplicada à criança na graduação

As três instituições pesquisadas assumem nos seus projetos pedagógicos o que é preconizado pelas Diretrizes Curriculares Nacionais (42), privilegiam o perfil generalista na formação e o desenvolvimento de valores e atitudes orientados para a cidadania, a integração com as demais instâncias do sistema de saúde e a interdisciplinaridade. A graduação promete habilitar o futuro profissional para ações de prevenção, promoção, proteção e reabilitação da saúde, tanto individual quanto coletiva.

A Fisioterapia aplicada à criança consta na grade curricular dos três cursos analisados, todos no formato disciplinar, assumindo diferentes denominações. Conforme o Quadro 1, observa-se que a primeira inserção destas disciplinas ocorre entre o 5ํ e 6o período, início da etapa profissionalizante dos cursos. A carga horária varia de 207 a 340 horas. Considerando a carga horária total dos cursos (4720, 4572 e 4000 respectivamente), o ensino dos conteúdos relacionados à Fisioterapia aplicada à criança ocupa um percentual de 7,20\%,5,73\%, 5,17\% respectivamente. Nas instituições "A" e "C", o estágio supervisionado obrigatório contempla horas exclusivas para as práticas assistenciais, ambulatoriais 
e hospitalares em Pediatria; na instituição "B", nos momentos de assistência ambulatorial, a experiência prática do estudante fica condicionada à sequência na admissão dos pacientes no serviço, não garantindo número de horas igual para todas as áreas contidas na grade curricular. As vivências práticas ocorrem de acordo com a demanda de casos no ambulatório.

Os conteúdos são distribuídos em duas disciplinas. Inicialmente em disciplinas denominadas como Clínica Pediátrica, Fisiopatologia Clínica em Pediatria e Neonatologia, e Fisioterapia Neurológica Pediátrica. Essas disciplinas propõem conhecimentos das doenças prevalentes na infância, privilegiando as doenças neurológicas e do aparelho respiratório. No segundo momento dos cursos, são apresentadas disciplinas com denominações diferentes, no entanto, com objetivos semelhantes: Fisioterapia aplicada à criança, Fisioterapia na criança. Nesse momento, o estudante tem acesso aos conhecimentos relacionados à avaliação e tratamento das doenças, com vivências práticas em contato com pacientes.

Os conteúdos são trabalhados em aulas expositivas, utilizando recursos audiovisuais, seminários, estudo de casos clínicos e práticas. As práticas no primeiro momento consistem em conhecer o atendimento em fisioterapia e doenças prevalentes nos serviços sem o contato direto com a criança. No segundo momento, as práticas contemplam a avaliação de casos e propostas de tratamento no atendimento a crianças com comprometimento motor.

No plano de ensino de uma das instituições foi encontrada proposta inovadora com apresentação da metodologia problematizadora na disciplina que contempla os conteúdos iniciais relacionados à criança.

$\mathrm{Na}$ análise temática do núcleo, 0 Ensino da Fisioterapia Aplicada à Criança, foram identificadas 48 unidades de contexto. A partir destas, foram encontradas 60 unidades de registro, distribuídas em quatro categorias e suas devidas subcategorias:

\section{a) Especificidades na terapêutica}

Especificidades na terapêutica foram ressaltadas pelos professores como característica a ser observada no ensino da Fisioterapia Aplicada à Criança: " $A$ terapia manual com a criança é diferente” (Sujeito A).

Diante da assertiva "A graduação favorece o desenvolvimento de habilidades avaliativas e procedimentos terapêuticos, com abordagem diferenciada para a criança", observou-se que a maioria dos alunos confirma que o ensino na graduação leva em conta essas especificidades.

A Interação-interface família e criança é considerada imprescindível na prática da Fisioterapia aplicada à criança pelos professores: "Tem que ter a vivência das relações interpessoais [...] além de ver a criança, você vai ver a família, a mãe, o cuidador" (Sujeito F).

Quando defrontados com a assertiva "A graduação prepara para interagir com os familiares sobre o processo de atenção a saúde da criança", observa-se que 55\% não tem opinião formada sobre o assunto, $15 \%$ discordam quanto ao preparo específico para a interação com os familiares.

Necessidade de visão holística e ênfase no desenvolvimento são também referidas: "Eu tento passar para os meus alunos que... eles possam atender de uma forma geral e especifica atendendo a necessidade de cada criança" (Sujeito L). Um dos professores distingue a necessidade de Criatividade para adequação terapêutica nessa prática: "Na pediatria precisa muito desenvolver a criatividade, precisa ser muito criativo" (Sujeito H).

Atualmente, a assistência à saúde da criança tem dado significativa importância às necessidades

Quadro 1 - Distribuição carga horária

\begin{tabular}{lcccccc}
\hline Instituição & $\begin{array}{c}\text { CHT } \\
\text { (horas/aula) }\end{array}$ & $\begin{array}{c}\text { Duração } \\
\text { (anos) }\end{array}$ & Natureza & $\begin{array}{c}\text { CHT/D } \\
\text { (horas/aula) }\end{array}$ & $\begin{array}{c}\text { Período inserção } \\
\text { Semestre }\end{array}$ & $\begin{array}{c}\text { Professores } \\
\text { (n) }\end{array}$ \\
\hline A & 4720 & 5 & Pública & 340 & 70 & 4 \\
B & 4572 & 5 & Privada & 262 & $6^{0}$ & 5 \\
C & 4000 & 5 & Privada & 207 & $5^{0}$ & 3 \\
\hline
\end{tabular}

Legenda: $\mathrm{CHT}=$ carga horária total do curso; $\mathrm{CHT} / \mathrm{D}=$ carga horária de Fisioterapia Aplicada à Criança.

Fonte: Guedes (43) 
afetivas, emocionais, sociais e culturais da criança (44). Já podem ser vistos como obrigatórios: permanência constante do familiar junto à criança hospitalizada; informações precisas sobre a sua doença e o tratamento; respeito às etapas evolutivas e aos marcos do desenvolvimento infantil; e oferecimento de um ambiente aconchegante onde a criança seja motivada a brincar de forma ativa $(45,46)$.

Entre as novas tendências filosóficas do cuidado à criança, destaca-se a prestação da assistência atraumática, que pressupõe intervenções voltadas a eliminar ou minimizar os desconfortos físicos e psicológicos experimentados pelas crianças e seus familiares, seja na realização de um procedimento ou quando vivenciam a internação hospitalar (44). Além de propiciar um ambiente humanizado, é assegurado à criança o acesso a brinquedos e jogos infantis.

Pela Declaração dos Direitos da Criança das Nações Unidas, a necessidade de brincar é vista como essencial à criança. 0 Estatuto da Criança e do Adolescente reafirma a importância do brincar, no Artigo 16, item IV - "brincar, praticar esportes e divertir-se" (47).

Os docentes, em sua maioria, praticam o planejamento de ensino junto com os colegas que dividem o conteúdo, favorecendo o planejamento em grupo. "Existem reuniões semestrais... a gente aproveita tanto pra discutir a vida da disciplina de base, no caso pediatria, quanto pra discutir alguns temas a serem abordados durante o período de estágio" (Sujeito A).

Uma das professoras comenta que ministra uma das disciplinas sozinha, mas que, nesse caso, tenta fazer seu planejamento de ensino com outros professores, favorecendo interação interdisciplinar: "Lá não tem como planejar porque eu sou sozinha, mas tento interagir com os outros professores" (Sujeito H).

0 planejamento, de um modo geral, diz respeito à intencionalidade da ação humana em contrapartida ao agir aleatoriamente (48), desconsiderando um fim, um objetivo e um agir de forma organizada para construir/atingir o resultado desejado.

0 professor deve sempre se perguntar o que seu aluno precisa aprender na disciplina para que se torne um profissional conforme definido pelo projeto pedagógico do seu curso; deve se perguntar também como fazer para que seu aluno descubra o valor e a importância da matéria que leciona e que se envolva com seu processo de aprendizagem. A compreensão do conceito desse processo altera significativamente a postura e as práticas pedagógicas dos docentes de
Ensino Superior. A partir dessa reflexão, o processo de aprendizagem na formação do cidadão será retomado em toda sua totalidade: inteligência, afetividade, política, economia e transcendências (49).

O planejamento de ensino, portanto, é uma construção orientadora da ação docente, que, como processo, organiza e direciona a prática coerente com os objetivos a que se propõe. Antes de iniciar o planejamento, o professor precisa conhecer o projeto pedagógico e o plano curricular do curso para nortear suas ações de planejamento. Depois, o docente precisa identificar o objeto planejado, justificar de modo claro o planejamento, conhecer a clientela-alvo de seu planejamento e pensar na metodologia adequada; portanto precisa se perguntar: 0 que está planejando? Por que planejar? Para quê? Como desenvolver este planejamento? Quando desenvolvê-lo? Tudo isso para situar no tempo a execução do planejado (50).

A interdisciplinaridade permite uma visão dos fenômenos de forma renovada, a partir de duas ou mais áreas do conhecimento que se integram. 0 professor que consegue planejar sua disciplina de modo a observar os fenômenos sob diferentes pontos de vista, de acordo com outras disciplinas do curso, procurando a integração, estará trabalhando com seu aluno a dimensão interdisciplinar. Aprender como promover a integração de saberes faz parte da formação pedagógica do docente do Ensino Superior nos dias de hoje (49).

\section{b) Estratégias de ensino}

Com relação às estratégias de ensino, observa-se que os professores utilizam uma diversidade de técnicas de ensino e de recursos instrucionais: "Multimídia, bonecos, dinâmicas (eles buscam o desenvolvimento deles), brinquedos artesanais, apresentação de trabalhos, aulas práticas com bonecos $e$ aulas práticas com eles e com o paciente; no estágio, usamos muito a discussão de caso clínico, explanação de patologias" (Sujeito B).

Sobre a metodologia utilizada, foi observado enfoque na metodologia tradicional, eminentemente transmissiva: "Acabo passando a patologia... a parte de fisiologia, anatomia da criança menor, de todas as patologias de modo geral" (Sujeito L).

No entanto, foram percebidos indícios de metodologia ativa como inovação metodológica nas falas de alguns professores: "No estágio vai muito da necessidade do aluno" (Sujeito $\mathrm{C}$ ). 
É de entendimento internacional a necessidade de mudança na educação de profissionais de Saúde perante a inadequação das Instituições de Ensino Superior em responder às demandas sociais (51).

No Brasil, as instituições de ensino em saúde têm sofrido exigências no sentido de se adequarem aos princípios do Sistema Único de Saúde (SUS). Entre essas exigências estão as de valorizar a equidade; a qualidade da assistência; a eficiência e relevância do trabalho em saúde. Esse processo de mudança da educação prevê inúmeros desafios, entre eles o de romper com estruturas estabelecidas e modelos de ensino tradicional e o de formar profissionais de Saúde com competências que lhes permitam recuperar a dimensão essencial do cuidado, que é a relação entre seres humanos (51).

O desafio do Ensino Superior está em formar indivíduos autônomos com senso de coletividade. A educação deve desencadear no estudante sentimentos de interdependência e transdisciplinaridade, de forma que favoreça a construção de redes de mudanças sociais. Para conseguir este intento há uma crescente tendência na busca inovadora de métodos de ensino que admitam uma prática pedagógica ética, crítica, reflexiva e, por isso, transformadora, ultrapassando os limites do treinamento puramente técnico, para efetivamente alcançar a formação do homem como um ser histórico, inscrito na dialética da ação-reflexão-ação (52).

Mesmo que as inovações metodológicas não consigam mobilizar toda uma instituição de ensino, ainda assim, o interesse por mudanças inovadoras isoladas dentro da instituição, na contramão do modelo dominante de ensino e dentro de uma visão tecnicista e alienante, pode mobilizar processos significativos de mudança (53).

Dentro das metodologias inovadoras, estão a problematização e a aprendizagem baseada em problemas (ABP). São duas propostas diferentes, que trabalham propositalmente com problemas, objetivando o desenvolvimento dos processos de ensinar e aprender, amparadas na aprendizagem por descobertas significativas.

Dentre as estratégias utilizadas pelos professores foi observada uma diversidade de cenários para atividades práticas no ensino da Fisioterapia Aplicada à Criança: "A gente tem acesso a UTI neonatal, a unidade de cuidados intermediários, a unidade canguru, ao próprio alojamento conjunto" (Sujeito E). Um esforço de adequação de conduta para vivências práticas é também enfatizado: "Achei melhor levar para lá (Hospital
Santa Mônica), lá a gente tem uma liberdade boa de trabalhar" (Sujeito J).

Dificuldades na articulação de teoria e prática foram detectadas nas falas de alguns professores: "Poucas vezes tive a oportunidade de fazer prática aplicando a teórica, então qual é a prática que eu devo reforçar no período de estágio" (Sujeito A).

Quanto à assertiva "A interação entre o que foi trabalhado na teoria e o que se desenvolveu durante as práticas foi adequado para atuação na atenção à criança”, os resultados podem ser observados no Gráfico 1.

Apesar de o número de concordantes e discordantes estar equilibrado, a soma da população de discordantes e daqueles que não têm uma opinião formada sobre o assunto perfaz 58\% da amostra.

c) Desenvolvimento de conteúdo

No desenvolvimento de conteúdo foi ressaltado o privilégio de áreas específicas de conhecimento como a Neuropediatria e Respiratória: "Fico com a parte de neuropediatria... reflexos e reações e desenvolvimento neuropsicomotor" (Sujeito F); "Eu ensino Clínica em Pediatria voltada à parte respiratória e a prática em UTI neonatal (Sujeito D). Foi salientado predomínio hospitalar de ações em Fisioterapia Respiratória: "Eu fico mais voltada para as doenças que são atendidas no hospital [...] pra parte respiratória" (Sujeito I). Os professores salientaram a ênfase nas práticas terapêuticas mais prevalentes: "É interessante passar as técnicas práticas [...] mais utilizados pra tratar patologias pediátricas" (Sujeito B).

Dois docentes referiram-se à inserção de conteúdos relativos à criança em outras disciplinas, como

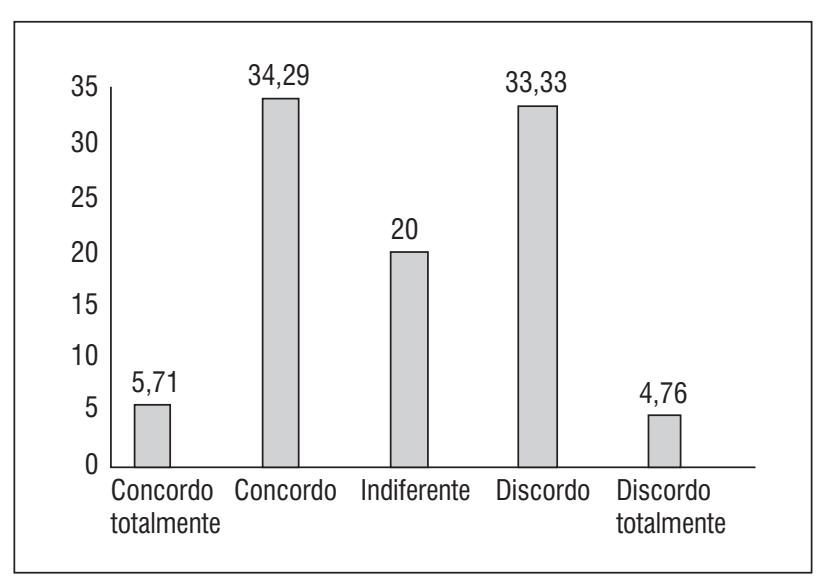

Gráfico 1 - Interação teoria e prática Fonte: Guedes (43). 
na Fisioterapia Preventiva e na Hidroterapia: “[...] estou na preventiva [...] onde o aluno tem oportunidade de vivenciar as ações de promoção da saúde voltadas para a criança: como amamentação, prevenção de acidentes, vacinação" (Sujeito J).

Diante da assertiva "A graduação em Fisioterapia prepara para o desenvolvimento de ações de promoção da saúde da criança", os resultados obtidos foram: pouco mais de $60 \%$ dos egressos são indiferentes e discordam do preparo para os cuidados de promoção da saúde da criança.

Ante a assertiva "A graduação prepara para tratar um dano já instalado", observa-se: concordância em $96,19 \%$ que a graduação os prepara para tratar um dano já instalado. No entanto, quanto à assertiva "A graduação prepara para fazer diagnóstico ou tratar precocemente", os egressos em sua maioria discordam; na opinião deles, a graduação não os prepara para a prevenção de danos, como se observa no Gráfico 2 .

No modelo de formação e, consequentemente, no perfil dos profissionais egressos, observa-se clara supremacia de formação curativo-reabilitadora, condição arraigada ao modelo original de formação, a reabilitação de indivíduos com sequelas e traumas e lesões no sistema musculoesquelético (54).

As particularidades de profissões historicamente inscritas no contexto da reabilitação, tal como a Fisioterapia, favorecem a cultura de atuação limitada à existência de amplas salas, equipamentos, recursos caros e dependentes de uma infraestrutura física e de material específico. Essa visão mantém a Fisioterapia à margem de muitas discussões que atualmente têm permitido avanços para outras profissões da Saúde (55).

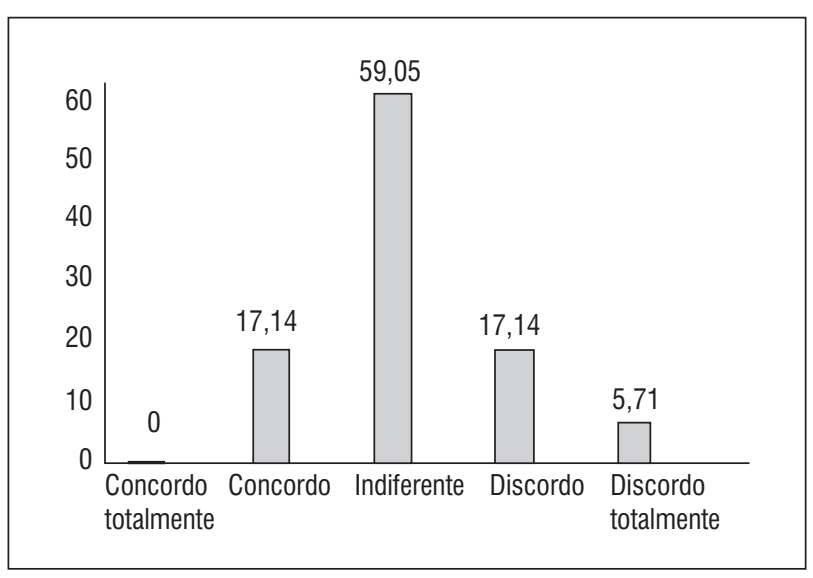

Gráfico 2 - Preparação para diagnóstico ou tratamento precoce

Fonte: Guedes (43). d) Estratégias de avaliação

Quanto às estratégias de avaliação utilizadas pelos professores, foram identificadas 28 unidades de contexto, com 38 unidades de registro, agrupadas em três categorias de análise:

Na avaliação do aprendizado, a habilidade teórica do estudante é a ênfase mais apontada pelos professores: "Prova; avaliação escrita teórica" (Sujeito A). Nas falas de dois professores, a preferência por avaliação teórica que favoreça a realimentação para direcionamento do ensino é enfatizada: "Discussões de caso, porque eu acho que dá um feedback pra gente" (Sujeito E). A avaliação das atividades prática surge como estratégia de avaliação: "A gente avalia nas práticas com o atendimento" (Sujeito L).

A avaliação é como uma ação provocativa do professor, desafiando o aluno a refletir sobre as experiências vividas, a formular e reformular hipóteses, direcionando para um saber enriquecido (56).

A avaliação da aprendizagem não possui uma finalidade em si mesma, ela subsidia a ação na construção do resultado previamente definido. Adquire sentido à medida que se articula com o projeto pedagógico e de ensino. A avaliação subsidia as decisões a respeito da aprendizagem dos estudantes, tendo em vista garantir os resultados previstos no projeto de ensino (57).

A avaliação destina-se a servir de base para a tomada de decisão, com o objetivo de construir no e com o estudante conhecimentos, habilidade e hábitos que possibilitem o seu efetivo desenvolvimento.

Existe distinção entre os conceitos de verificação e avaliação de aprendizagem a partir da atitude tomada diante do resultado da aferição. Dependendo de como o professor trata os dados obtidos na aferição do aprendizado, ele verificará ou avaliará o aprendizado. No momento em que o professor está com os resultados em mãos pode simplesmente registrá-lo no diário ou caderneta, pode, caso o estudante não tenha atingido o conceito ou a nota desejados, oferecer oportunidade para melhorar e atentar para as dificuldades do aluno, e trabalhar para que o estudante aprenda efetivamente o que deveria aprender (57).

\section{Propostas de aprimoramento para o ensino da Fisioterapia aplicada à criança}

Em face da assertiva "Se eu fosse o coordenador do curso de graduação em Fisioterapia da minha 
faculdade, faria mudanças em relação ao preparo do Fisioterapeuta para futura atuação na atenção à criança", foram os seguintes resultados obtidos: Mais de $72 \%$ dos estudantes entrevistados fariam mudanças no modelo vivenciado.

Em um segundo momento, os estudantes foram questionados sobre o que mudariam no ensino de Fisioterapia aplicada à criança: $10 \%$ disseram que fariam mudanças na carga horária teórica dos seus cursos; $80 \%$ aumentariam a carga horária de práticas em Fisioterapia aplicada à criança; $38 \%$ desejariam alterar a metodologia de ensino; $45 \%$ ampliariam os cenários de estágios no setor público e, por fim, $5 \%$ ampliariam os espaços físicos dos ambulatórios, laboratórios e salas de aula.

Na visão docente, as propostas de aprimoramento do ensino se apresentaram nas entrevistas em 48 unidades de registro, distribuídas em quatro categorias de análise.

Entre essas alterações, os professores sugerem ampliação e antecipação das vivências práticas: "Ter mais experiência na parte prática" (Sujeito F). Dois professores ressaltam a necessidade de inserção de novos conteúdos no ensino de Fisioterapia aplicada à criança com o objetivo de corrigir privilégios de áreas específicas: "A faculdade não possui uma disciplina em neonatal" (Sujeito H). Dois outros professores apontam ampliação da carga horária da disciplina, como necessidade no aprimoramento do ensino: "A gente deu a disciplina de fisioterapia aplicada à pediatria onde a carga horária não cobre nem neuropediatria" (Sujeito L). Dois professores ressaltaram a problematização do ensino como atividade que deve ser ampliada para aprimorar o ensino: "Acho que teria que ter mais espaço de problematização" (Sujeito H). Para que isso ocorra, o professor refere-se à melhoria da cultura institucional, de modo a torná-la aceitável como prática no ambiente acadêmico: "Sair das disposições, que é até pela questão do tempo, da própria cultura das pessoas aceitarem menos a questão da problematização" (Sujeito H). Dois professores trazem, em suas falas, a necessidade de implementar ações multidisciplinar e interdisciplinar no ensino de Fisioterapia aplicada à criança: "Eu acho que o atendimento multidisciplinar deveria ficar mais claro pro aluno" (Sujeito F).

Em assertiva direcionada aos egressos quanto à necessidade de mais vivências interdisciplinares no ensino de Fisioterapia Aplicada à Criança durante a graduação, os dados revelam: dos egressos, aproximadamente $70 \%$ concordam com essa necessidade.

Dois docentes trazem em suas falas a melhoria da aprendizagem individual do estudante como facilitador no aprimoramento do ensino na Fisioterapia aplicada à criança: "Melhorar a teoria dele antes, pra quando chegar na prática e olhar para uma coisa lá atrás, achar que não viu antes" (Sujeito H). Os egressos concordam que necessitam de mais conhecimento teórico para o exercício prático da profissão, considerando o que foi trabalhado durante o curso.

Um professor refere-se à necessidade de melhoria da articulação teórica e prática para o aprimoramento do ensino: "O que seria ideal é que a prática sempre caminhasse junto com a teórica, o tempo todo" (Sujeito D).

Quanto à assertiva "A integração entre o que foi trabalhado na teoria e o que se desenvolveu durante as práticas foram adequados para a atuação em Fisioterapia Aplicada à Criança”, os que discordaram ou não têm opinião formada sobre a questão perfazem $55 \%$ da amostra. Uma das necessidades apontadas é a ampliação do atendimento à população com maior abertura à demanda da comunidade: "A demanda de [...] crianças é muito pequena" (Sujeito A). Um professor sinaliza a necessidade de capacitação de recursos humanos para a melhoria do ensino de Fisioterapia aplicada à criança: "Desses todos que trabalham com a pediatria, quantos são mesmo da área?” (Sujeito I).

A melhoria de estrutura física nos ambulatórios e a criação de espaço físico nos hospitais para o ensino são apontadas por dois professores: "Estrutura em algumas instituições" (Sujeito I).

Um professor coloca a ampliação de cenários de prática como necessidade no ensino da Fisioterapia aplicada à criança: "Sinto falta de serviços mais abertos pra visita [...] clínicas que já tem esse atendimento" (Sujeito J). Os egressos concordam com a assertiva de que necessitam aprimorar atitudes interpessoais no exercício prático da profissão, considerando o que foi trabalhado na graduação.

\section{Conclusão}

Este trabalho procurou refletir as práticas de ensino-aprendizagem na área da Fisioterapia aplicada à criança no estado de Alagoas, sem a pretensão de dar conta de toda a complexidade que é o processo ensino-aprendizagem nesta situação específica. Apresenta-se como um convite aos profissionais envolvidos na 
atenção à criança a continuarem contribuindo e buscando respostas às questões que afetam esse ensino.

0 ensino de Fisioterapia aplicada à criança em Alagoas sofre as consequências do crescimento explosivo do número de cursos nesta última década. Em Alagoas, o número de cursos aumentou 700\%, em 13 anos, e de forma desordenada, pois todos os cursos concentram-se na capital do estado. Os professores responsáveis por esse ensino assumem contratos em regime parcial com mais de uma instituição.

No estado, não há Pós-Graduação Stricto Sensu para suprir as necessidades locais. No momento desta pesquisa, $70 \%$ dos professores estavam cursando mestrado via convênio interinstitucional no esforço de fazer cumprir a Lei de Diretrizes e Bases da Educação Superior.

0 ensino demonstrou práticas tradicionais da Fisioterapia voltadas para as doenças e, entre estas, as doenças neurológicas e afecções respiratórias. Os professores com formação docente demonstraram iniciativas em metodologias ativas e visão mais integral da saúde das crianças nas suas práticas de ensino.

Docentes e egressos apontaram vias de aprimoramento na formação de fisioterapeutas do estado de Alagoas no tocante ao seu papel na atenção à criança. Nesse sentido recomendam:

- alterações no projeto pedagógico - docentes e egressos sugerem ampliação e antecipação das vivências práticas; os docentes sugerem a inserção de novos conteúdos disciplinares e ampliação da carga horária das disciplinas;

- mudanças na metodologia de ensino - os docentes sugerem ampliação da problematização no ensino e mais apoio institucional a essas mudanças; implementação de ações inter e multidisciplinares; docentes e egressos concordam com a necessidade de melhorias na articulação teórico-prática;

- melhorias na infraestrutura dos cursos, no tocante à ampliação dos cenários de práticas no setor público - os professores sugerem a capacitação docente, melhoria e criação de espaços físicos para práticas desse ensino.

\section{Referências}

1. Gomes PJA. Criança e a nova pediatria: textos de educação. Lisboa: Fundação Calouste Gulbenkian; 1999.
2. Torralva T, Cugnasco I, Manso M, Sauton F, Ferrero M, O`donnell A, et al. Desarrollo mental y motor em los primeiros años de vida: su relación com la estimulacion ambiental y el nível socioeconômico. Arch. 1999;97(5)306.

3. Sanches SDO, Guerra L, Luft CDB, Andrade A. Perfil psicomotor associado a aprendizagem escolar. Enfermeria Del Deport y la actividad para la Salud. 2004;79(10).

4. Perpétuo AMA. A prática pedagógica do fisioterapeuta docente. [dissertação]. Curitiba: Pontifícia Universidade Católica do Paraná, 2005.

5. Zedaferino AMB, Barros A Filho. A capacitação docente: experiências da pós-graduação da saúde da criança e adolescente com a disciplina Pedagogia Médica e Didática Especial na FCM \UNICAMP. In: Batista NA, Batista SHS. Docência em Saúde: temas e experiências. São Paulo: SENAC; 2004. p. 225-35.

6. Franco MLPB. Análise de conteúdo. Brasília: Líber Livros; 2005.

7. Gil AC. Metodologia do ensino superior. São Paulo: Atlas; 1990

8. Backer P. Gestão Ambiental: a administração verde. Rio de Janeiro: Qualitymark; 1995.

9. Pereira LA, Almeida M. Dinâmicas das graduações em saúde no Brasil: subsídios para uma política de recursos humanos. Brasília: Ministério da Saúde; 2006. p. 171-84.

10. Brasil. Instituto Nacional de Estudo e Pesquisa Educacionais Anísio Teixeira-Inep. [acesso 15 maio 2010]. Disponível em: http://www.inep.gov.br.

11. Neves CEB, Raizer L, Fachenetto RF. Acesso, expansão e equidade na educação: novos desafios para a política educacional brasileira. Sociologias. 2007;17(9):124-57.

12. Brasil. Lei de Diretrizes e Bases da Educação Nacional: n. 9.394, de 20 de dezembro de 1996. [Acesso 5 set. 2010]. Disponível em: portal. mec.gov.br/arquivos/ pdf/ldb.

13. Coury HJCG, Vilella I. Perfil do pesquisador fisioterapeuta brasileiro. Rev. Brasileira de Fisioterapia. 2009;4(13):356-63. 
14. Gatti BA. A Formação dos docentes: o confronto necessário professor x academia. Cadernos de Pesquisa. 1992;81:70-4.

15. GIL AC. Metodologia do ensino superior. São Paulo; Atlas. 1990.

16. Zabalza AM. O Ensino universitário: seu cenário e seus protagonistas. Porto Alegre: Artmed; 2004.

17. Pimenta SG, Anastasiou LGC. Docência no ensino superior. São Paulo: Cortez; 2002.

18. Batista NA, Silva SMS. O professor de medicina. São Paulo: Loyola; 2001.

19. Fontana RAC. Como nos tornamos professoras? Belo Horizonte: Autêntica; 2000.

20. Kramer S, Jobim S, Souza S. Histórias de professores. São Paulo: Ática; 1996.

21. Perrenoud P, Nóvoa, Faria H. Práticas pedagógicas, profissão docente e formação: perspectivas sociológicas; 1993.

22. Garcia CM, Narciso I. Formação de professores: para uma Mudança Educativa; 2005.

23. Pimentel A, Araújo LS. Concepção de criança na pós-modernidade. Psicol. Cienc. Prof. 2007;2(7).

24. Brasil. Ministério da Saúde. Estatuto da criança e do adolescente. Brasília: Ministério da Saúde; 1991.

25. Oselka G, Troster EJ. Aspectos éticos do atendimento médico do adolescente. Rev Assoc Med Brás. 2000;4(46).

26. Shephert RB. Fisioterapia em pediatria. 3. ed. São Paulo: Livraria Santos; 1996.

27. Dallari DA, Korczac J. 0 direito da criança ao respeito. 2. ed. São Paulo: Summus; 1986.

28. Gaiva AMAM, Paião MRRS. 0 ser criança: percepção de alunas de um curso de graduação em enfermagem. Rev. Latino-Am. Enfermagem. 1999;1(7).

29. Takes K, Meeuwesen L. Doctor-patient-child communication. A (re)view of the literature. Soc. Sci. Méd. 2001;52 839-85. doi:10.1016/ S0277-9536(00)00193-3.

30. Hart C, Chersson R. Children as consumers. Br. Med. J. 1998;316:1600-3. doi:10.1136/bmj.316.7144.1600.
31. Piaget J. Desenvolvimento e aprendizagem. Studying teaching; 1972.

32. Chiarottino ZR. Em busca do sentido da obra de Jean Piaget. São Paulo: Ática; 1984.

33. Rebelatto JR, Botomé SP. Fisioterapia no Brasil. 2. ed. São Paulo: Manole; 1999.

34. Meyer PF, Costa ICC, Gico VV. Ciências sociais e Fisioterapia: uma aproximação possível. História, Ciências, Saúde. 2006;4(13):877-90.

35. Guedes EM. Fracasso Escolar: a palavra. Curitiba: HD Livros; 2000.

36. Hallstrom I, Elander G. Involving parents and families in clinical nursing: decision-making during hospitalization: parents' and children's involvement. J. Clin. Nurs. 2002;6(13):367.

37. Maldonado MT, Canella P. Recursos de relacionamento para profissionais de saúde: a boa comunicação com clientes e seus familiares em consultórios, ambulatórios e hospitais. Rio de Janeiro: Reichmann \& Affonso Editores; 2003.

38. Silva MJP. O Amor é o caminho: maneiras de cuidar. São Paulo: Gente; 2000.

39. Ramalhão AB, Dupas G. Vivendo ambivalências: o significado da visita para os pais de neonatos internados em unidades de tratamento intensivo. Acta Paul. Enf. São Paulo. 2003;3(16):45-50.

40. Munari DB, Furegato ARF. Enfermagem e Grupo. Goiânia: AB; 2003. PMCid:1738223.

41. Collet N, Oliveira BRG. Manual de enfermagem em pediatria. Goiânia: AB; 2002.

42. Brasil. Diretrizes Curriculares Nacionais do Curso de Graduação em Fisioterapia. 2002;1(11).

43. Guedes MJP. O Ensino e práticas da fisioterapia aplicada à criança na formação profissional do fisioterapeuta no estado de Alagoas; 2010.

44. Whaley LF, Wong DL. Enfermagem pediátrica: elementos essenciais à intervenção efetiva. 5. ed. Rio de Janeiro: Guanabara Koogan; 1999.

45. Vieira MA, Lima RAG. Convivendo com mudanças: vivências de crianças e adolescentes com doença crônica. Rev Lat Em Enferma. 2002;3(10) 23-30. 
46. Oliveira VRJ. Educação em saúde: notas para discussão de um tempo temático. Saúde em Debate. 1994;42.

47. Brasil. Estatuto da criança e do adolescente. Ministério da Saúde. 2. ed. Brasília: Atual; 2003. (Série E. Legislação de Saúde).

48. Luckesi CC. Planejamento e avaliação na escola: articulação e necessária determinação ideológica em o diretor - articulador do projeto da escola. Série Ideias. São Paulo: F.D.E.; 1992. p. 125-25.

49. Masetto MT. Formação pedagógica dos docentes do ensino superior. Revista Brasileira de Docência: ensino e pesquisa em administração. 2009;2(1):4-25.

50. Batista N, Batista SH. A docência em saúde: desafios e perspectivas. In: Batista N, Batista SH, organizadores. Docência em saúde: temas e experiências. São Paulo: SENAC; 2004.

51. Cyrino EG, Toralles PML. Trabalhando com estratégias de ensino-aprendizado por descoberta na área da saúde: a problematização e a aprendizagem baseada em problemas. Cad. Saúde Pública. 2004;3(20).

52. Mitre SM, Batista SR, Mendonça G, Morais-Pinto ND, Meirelles CDAB, Hoffmann LMA. Metodologias ativas de ensino-aprendizagem na formação profissional em saúde: debates atuais. Ciênc. saúde coletiva. 2008;13(2):2133-44.
53. Cunha MI, Fernandes CM, Foster MM. Avaliação externa e os cursos de graduação: implicações políticas na prática pedagógica e na docência. Avaliação. 2003;1(8).

54. Bispo JP Junior. Formação em Fisioterapia no Brasil: reflexões sobre a expansão do ensino e os modelos de formação. História, Ciências, Saúde. 2009;3(16):655-68.

55. ABRASCO. Associação Brasileira de Saúde Coletiva. A fisioterapia na saúde coletiva: buscando enfrentar os desafios da integralidade da atenção. Anais do VI Congresso Brasileiro de Saúde Coletiva; 2003; Brasília.

56. Hoffmann J. Avaliação mediadora: uma prática em construção da pré-escola à universidade. 8. ed. Porto Alegre: Mediação; 1996.

57. Luckesi CC. Avaliação educacional escolar: para além do autoritarismo. Rev Tecnologia educacional. 1984;61:6-15.

Recebido: 28/03/2012

Received: 03/28/2012

Aprovado: 09/11/2012

Approved: 11/09/2012 